\title{
Ethical Concerns in the Care of Patients with Advanced Kidney Disease: a National Retrospective Study, 2000-2011
}

\author{
Catherine R. Butler, $M D^{7}$, Elizabeth K. Vig, MD, $M P H^{2,3}$, Ann M. O'Hare, $M D, M A^{1,4}$, \\ Chuan-Fen Liu, PhD ${ }^{4,5}$, Paul L. Hebert, PhD ${ }^{4,5}$, and Susan P.Y. Wong, MD, MS 1,4
}

'Division of Nephrology, Department of Medicine, University of Washington, Seattle, WA, USA; ${ }^{2}$ Geriatrics and Extended Care, VA Puget Sound Healthcare System, Seattle, WA, USA; ${ }^{3}$ Division of Gerontology and Geriatric Medicine, Department of Medicine, University of Washington, Seattle, WA, USA; ${ }^{4}$ Health Service Research and Development Center of Innovation, VA Puget Sound Healthcare System, Seattle, WA, USA; ${ }^{5}$ Department of Health Services, University of Washington, Seattle, WA, USA.

BACKGROUND: Understanding ethical concerns that arise in the care of patients with advanced kidney disease may help identify opportunities to support medical decision-making.

OBJECTIVE: To describe the clinical contexts and types of ethical concerns that arise in the care of patients with advanced kidney disease.

DESIGN: Retrospective cohort study.

PARTICIPANTS: A total of 28,568 Veterans with advanced kidney disease between 2000 and 2009 followed through death or 2011.

EXPOSURE: Clinical scenarios that prompted clinicians to consider an ethics consultation as documented in the medical record.

MAIN MEASURES: Dialysis initiation, dialysis discontinuation, receipt of an intensive procedure during the final month of life, and hospice enrollment.

KEY RESULTS: Patients had a mean age of 67.1 years, and the majority were male (98.5\%) and white (59.0\%). Clinicians considered an ethics consultation for 794 patients $(2.5 \%)$ over a median follow-up period of 2.7 years. Ethical concerns involved code status (37.8\%), dialysis (54.5\%), other invasive treatments (40.6\%), and noninvasive treatments $(61.1 \%)$ and were related to conflicts between patients, their surrogates, and/or clinicians about treatment preferences $(79.3 \%)$, who had authority to make healthcare decisions (65.9\%), and meeting the care needs of patients versus obligations to others (10.6\%). Among the 20,583 patients who died during follow-up, those for whom clinicians had considered an ethics consultation were less likely to have been treated with dialysis (47.6\% versus $62.0 \%$, adjusted odds ratio [aOR] 0.63 , 95\% CI 0.53-0.74), more likely to have discontinued dialysis (32.5\% versus $20.9 \%$, aOR 2.07 , CI 1.61-2.66), and less likely to have received an intensive procedure in the last month of life $(8.9 \%$ versus $18.9 \%$, aOR 0.41 , CI 0.32 0.54) compared with patients without documentation of clinicians having considered consultation.

CONCLUSIONS: Clinicians considered an ethics consultation for patients with advanced kidney disease in

Electronic supplementary material The online version of this article (https://doi.org/10.1007/s11606-019-05466-w) contains supplementary material, which is available to authorized users.

Received March 18, 2019

Revised July 26, 2019

Accepted September 19, 2019

Published online October 25, 2019 situations of conflicting preferences regarding dialysis and other intensive treatments, especially when these treatments were not pursued.

KEY WORDS: ethics; kidney disease; end of life care; palliative care; intensive care.

$\mathrm{J}$ Gen Intern Med 35(4):1035-43

DOI: $10.1007 / \mathrm{s} 11606-019-05466-\mathrm{w}$

(c) Society of General Internal Medicine 2019

\section{INTRODUCTION}

The field of clinical bioethics has evolved in response to moral uncertainty and conflict about the provision of life-prolonging medical technologies including dialysis, mechanical ventilation, cardiopulmonary resuscitation (CPR), and artificial nutrition. ${ }^{1,2}$ Advances in medical science have broadened treatment options and offered new opportunities to improve health and lengthen life. This diversity of treatment options has also led to extraordinarily complex medical decision-making that is increasingly dependent on not only the clinical facts but the perspectives and values of patients, families, and clinicians. These stakeholders can have widely discordant beliefs and preferences about treatment strategies, ${ }^{3,} 4$ and unresolved conflict can engender dissatisfaction and mistrust toward the healthcare system among patients and families ${ }^{5,6}$ and moral distress among clinicians. ${ }^{7}$

Ethical questions arising in the care of patients with kidney disease have been especially challenging. In the 1960s, concerns about how to fairly allocate a limited number of dialysis machines among patients with advanced kidney disease informed the development of early bioethical paradigms. ${ }^{1}$ Today, the conversation has shifted to questions about how to best care for patients who are unlikely to benefit from dialysis treatment. $^{8-11}$ Patients with advanced kidney disease also tend to be older and medically complex, ${ }^{12}$ leading to frequent interactions with the health system in which they may be faced with a variety of treatment decisions both related and unrelated to their underlying kidney disease. ${ }^{13-15}$

In 1992, amid a growing number of bioethical concerns in medical practice, the Joint Commission on Accreditation of 
Health Care Organizations (JCAHO) required that all hospitals establish a mechanism to facilitate resolution of ethical conflicts. ${ }^{16}$ The Department of Veterans Affairs (VA) - the largest integrated healthcare system in the USA - has been especially proactive in establishing ethics consultation services at all of its facilities. ${ }^{17}$ Comprised of staff with diverse healthcare backgrounds, the VA ethics consultation service serves as a resource to help address ethical issues that arise in patient care and healthcare management by providing ethical case analysis, conflict mediation, outreach and education, and development and interpretation of organizational policy. ${ }^{18,} 19$

Investigation into the kinds of clinical circumstances that prompt clinicians to consider an ethics consultation may elucidate some of the most ethically challenging aspects of clinical practice and identify those patients who experience the greatest burden of value conflict during the course of their care. To our knowledge, available literature describing patterns of ethics consultation is largely limited to clinician surveys, ${ }^{20,}{ }^{21}$ case series, and single-center studies, ${ }^{22-25}$ and none target the population of patients with kidney disease. We conducted a mixed methods retrospective study to describe the clinical context in which clinicians considered an ethics consultation and to examine associated patterns of care among a national cohort of patients with advanced kidney disease receiving care in the VA.

\section{MATERIALS AND METHODS}

\section{Study Population}

The analyses described here were conducted among a previously defined national cohort of 28,568 patients aged $\geq 18$ years with advanced kidney disease who received care in the VA. As described in detail elsewhere, ${ }^{26,} 27$ advanced kidney disease was defined as having at least two outpatient measures of estimated glomerular filtration rate (eGFR) $<15 \mathrm{ml} / \mathrm{min} /$ $1.73 \mathrm{~m}^{2}$ separated by at least 90 days. Patients entered the cohort on the date of their second eGFR $<15 \mathrm{ml} / \mathrm{min} / 1.73 \mathrm{~m}^{2}$ between January 1, 2000, and December 31, 2009, and were followed through their date of their death or October 1, 2011. The Institutional Review Boards at the VA Puget Sound Health Care System and the University of Washington approved this study and waived the requirement for informed consent.

\section{Patient Characteristics}

Using the VA Vital Status File, we ascertained patients' age at cohort entry, race, and sex. From the VA Decision Support System Laboratory Results File, we collected outpatient serum creatinine measures that we then used to calculate each patient's eGFR at cohort entry. We used linked Medicare and VA files to identify whether patients had the following comorbid conditions based on relevant International Classification of Disease- 9 codes documented on at least two claims during the year before cohort entry: coronary artery disease, congestive heart failure, diabetes mellitus, peripheral artery disease, chronic obstructive pulmonary disease, cancer, dementia, depression, stroke, post-traumatic stress disorder, and substance use disorder. For each patient, we calculated a Gagne comorbidity score to estimate overall burden of comorbidity based on relevant diagnostic codes in Medicare and VA files during the year before cohort entry. ${ }^{28}$

\section{Clinical Circumstances Prompting Clinicians to Consider an Ethics Consultation}

In order to include a range of clinical contexts associated with ethical concern, we used a broad search strategy to identify cohort members who had chart documentation indicating that clinicians had at least considered an ethics consultation. The VA maintains a national electronic medical record that includes progress notes for inpatient and outpatient encounters at all of its facilities. We used Lucene text-searching software ${ }^{29}$ to select all patients with at least one progress note containing the term "ethics" in the note title or body of the text (hereafter referred to as an "ethics reference") in their electronic medical record between the time of cohort entry and the end of follow up $(n=1,222)$ (Fig. 1). Then, one author (C.R.B., a senior nephrology fellow) reviewed all ethics references identified by text search to determine whether each reference related to ethics consultation. We included in our analysis patients for whom an ethics consultation was documented in a formal ethics note or under the note title of the consultant's primary service (e.g., social work, palliative care), patients whose clinicians documented interactions with the ethics consultation service but for whom we did not identify a formal ethics

Patients $18+$ with eGFR $<15 \mathrm{ml} / \mathrm{min} / 1.73 \mathrm{~m} 2$ in the VA from 2000-2009 who had not started dialysis prior to cohort entry $\mathrm{N}=28,568$

Followed through first service date in USRDS, first dialysis procedure code in Medicare/VA administrative data, and date of death or $10 / 1 / 11$

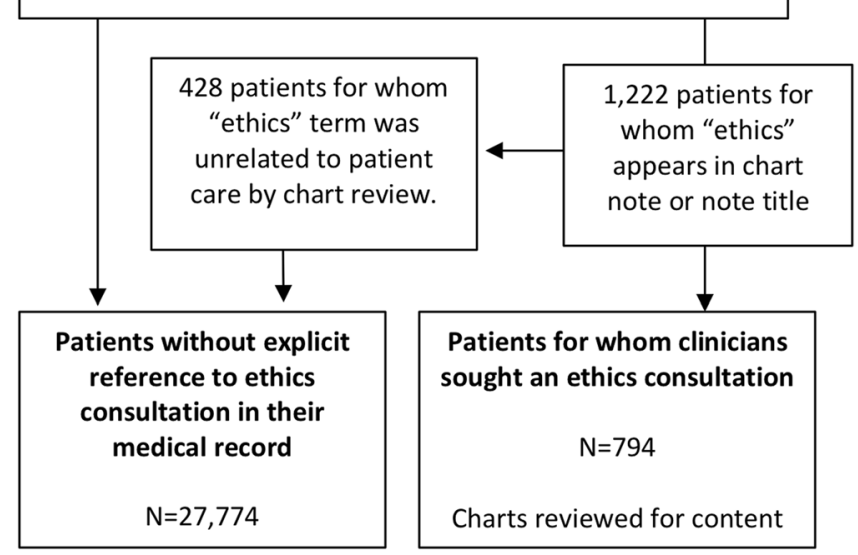

Figure 1 Flowchart showing derivation of the cohort. Detailed cohort derivation has been previously published. ${ }^{30}$ Abbreviations: estimated glomerular filtration rate (eGFR), US Renal Data System (USRDS), Veterans Affairs (VA). 
consultation note, and those whose clinicians documented having considered an ethics consultation but had no further documentation of whether this occurred (Online Appendix Table 1). Those with ethics references that were unrelated to clinical care $(n=$ 428), such as when the term "ethics" appeared as part of a generic note template, were excluded from the analysis (Online Appendix Table 1).

We performed a combination of inductive and deductive content analyses of clinical progress notes for all patients for whom clinicians had considered ethics consultation $(n=$ 794). Inductive content analysis is an unstructured approach to the reading of texts aimed at generating concepts or themes inherent to a phenomenon that have not previously been described. ${ }^{31}$ In deductive content analysis, the investigator approaches the text with an established conceptual framework in mind and an aim to determine whether a particular occurrence is consistent with previously described categories. ${ }^{31}$ Using this approach, two authors (C.R.B. and S.P.Y.W., a nephrologist) selected a sample of 200 patients for whom clinicians had considered an ethics consultation and performed an in-depth review of all progress notes containing an ethics reference as well as progress notes, admission notes, and discharge summaries in the medical record around the time of the ethics reference(s). If there were multiple ethics references in the medical record of a single patient, they were considered together to determine the overall clinical circumstance raising ethical concern. Using an iterative process, we then developed a thematic framework to classify each patient's clinical circumstances into descriptive categories. We further refined category definitions in discussion with two other authors (A.M.O., a nephrologist, and E.K.V., a bioethicist, geriatrician, and palliative care physician). Using the final conceptual framework, one author (C.R.B.) assigned the remaining cohort members for whom clinicians had considered an ethics consultation $(n=594)$ to the pre-specified categories.

\section{End-of-life Care}

We used the VA Vital Status file to identify patients who died during follow-up. We used VA and Medicare files to determine whether decedents had received an intensive procedure (CPR, mechanical ventilation, and/or artificial enteral nutrition) during their last month of life and whether they had enrolled in hospice prior to death. Among patients who died during follow-up, we also determined whether patients had been treated with dialysis based on enrollment in the United States Renal Dialysis System (USRDS), a national registry of patients receiving maintenance dialysis, and dialysis procedure code search of Medicare and VA files. Among those decedents who appeared in the USRDS registry during follow-up, we used information from the Center for Medicare and Medicaid Services (CMS) Death Notification Form to ascertain whether they had discontinued dialysis before death.

\section{Analytic Approach}

We used proportions and chi-squared tests or means and ANOVA to describe and compare the characteristics of patients for whom there was documentation indicating that clinicians had considered an ethics consultation and those without such documentation in their medical record. In analyses restricted to those who died during follow-up $(n=20,583)$, we compared patterns of end-of-life care between the two groups using logistic regression analyses adjusted for all measured patient characteristics and the year of cohort entry. Statistical analyses were performed using SPSS, version 19 (IBM SPSS, Chicago, IL).

\section{RESULTS}

Over a median follow-up of 2.7 years (interquartile range [IQR] 0.9-4.8 years), there was documentation indicating that clinicians had considered an ethics consultation for 794 patients $(2.8 \%)$. Among members of this group, the earliest ethics reference was documented a median of 88 days (IQR 16-462 days) before the end of follow-up. Among the subset of 694 patients $(87.4 \%)$ in this group who died during followup, the earliest ethics reference was documented a median of 63 days (IQR 13-300 days) before their death. Patients for whom clinicians had considered an ethics consultation were less often white and had a higher overall burden of comorbidity compared with patients without documentation suggesting that this had occurred (Table 1). Individual comorbidities including congestive heart failure, peripheral arterial disease, chronic obstructive pulmonary disease, dementia, depression, stroke, post-traumatic stress disorder, and substance use disorder were also more prevalent among patients for whom clinicians had considered an ethics consultation.

\section{Clinical Circumstances Prompting Clinicians to Consider and/or Complete an Ethics Consultation}

Based on content analysis of progress notes, we constructed two schemas to describe the clinical context in which clinicians considered an ethics consultation. The first reflected the types of treatments involved and included (1) code status; (2) dialysis; (3) other invasive treatments (mechanical ventilation, surgery, and/or artificial enteral nutrition); and (4) noninvasive interventions (e.g., medications, blood transfusions, discharge planning). The second schema reflected the types of conflict prompting clinicians to consider and/or complete an ethics consultation and included (1) treatment preferences: uncertainty or disagreement about preferences for treatment(s) between or among patients, their surrogates, family members, and/or clinicians; (2)decision-making authority: uncertainty or disagreement about the patient's decision-making capacity, who should serve as their surrogate, and/or the role of the surrogate; (3) resource/policy: conflict between meeting the care needs of 
Table 1 Characteristics of Patients in Whom an Ethics Consultation Was or Was Not Sought

\begin{tabular}{|c|c|c|c|}
\hline & $\begin{array}{l}\text { Patients without } \\
\text { a chart reference } \\
\text { to ethics } \\
\text { consultation, \% } \\
(n=27,774)\end{array}$ & $\begin{array}{l}\text { Patients for } \\
\text { whom clinicians } \\
\text { sought an ethics } \\
\text { consultation, \% } \\
(n=794)\end{array}$ & $\begin{array}{l}p \\
\text { value* }\end{array}$ \\
\hline $\begin{array}{l}\text { Age at cohort } \\
\text { entry, mean (SD) }\end{array}$ & $67.1(11.5)$ & $66.8(12.0)$ & 0.46 \\
\hline $\begin{array}{l}\text { Age group at } \\
\text { cohort entry, y }\end{array}$ & & & 0.34 \\
\hline $\begin{array}{l}<65 \\
65-74 \\
75-84 \\
\geq 85\end{array}$ & $\begin{array}{l}42.2 \\
27.4 \\
25.4 \\
5.0\end{array}$ & $\begin{array}{l}43.8 \\
25.7 \\
24.4 \\
6.0\end{array}$ & \\
\hline $\begin{array}{l}\text { Sex } \\
\text { Male }\end{array}$ & 98.5 & 99.0 & 0.27 \\
\hline $\begin{array}{l}\text { Race } \\
\text { White } \\
\text { Black } \\
\text { Other }\end{array}$ & $\begin{array}{l}59.0 \\
29.4 \\
11.6\end{array}$ & $\begin{array}{l}48.7 \\
32.0 \\
19.3\end{array}$ & $<0.001$ \\
\hline $\begin{array}{l}\text { Comorbidities } \\
\text { Coronary } \\
\text { artery disease }\end{array}$ & 39.4 & 39.0 & 0.84 \\
\hline $\begin{array}{l}\text { Congestive } \\
\text { heart failure }\end{array}$ & 31.6 & 35.5 & 0.02 \\
\hline $\begin{array}{l}\text { Diabetes } \\
\text { mellitus }\end{array}$ & 59.3 & 58.1 & 0.49 \\
\hline $\begin{array}{l}\text { Peripheral } \\
\text { artery disease }\end{array}$ & 13.7 & 14.2 & 0.66 \\
\hline $\begin{array}{l}\text { Chronic } \\
\text { obstructive } \\
\text { pulmonary } \\
\text { disease }\end{array}$ & 17.9 & 21.3 & 0.02 \\
\hline Cancer & 20.5 & 18.4 & 0.15 \\
\hline Dementia & 2.5 & 6.2 & $<0.001$ \\
\hline Depression & 4.1 & 6.4 & 0.002 \\
\hline Stroke & 8.5 & 12.1 & $<0.001$ \\
\hline $\begin{array}{l}\text { Post-traumatic } \\
\text { stress disorder }\end{array}$ & 5.2 & 7.9 & $<0.001$ \\
\hline Substance use & 6.5 & 12.5 & $<0.001$ \\
\hline $\begin{array}{l}\text { Gagne } \\
\text { comorbidity } \\
\text { score, median } \\
\text { (IQR) }\end{array}$ & $4(3,6)$ & $5(3,8)$ & $<0.001$ \\
\hline $\begin{array}{l}\text { Year of cohort } \\
\text { entry }\end{array}$ & & & 0.64 \\
\hline 2000-2001 & 21.7 & 20.7 & \\
\hline $2002-2003$ & 20.4 & 18.9 & \\
\hline 2004-2005 & 21.9 & 21.5 & \\
\hline 2006-2007 & 18.6 & 20.5 & \\
\hline 2008-2009 & 17.3 & 18.4 & \\
\hline
\end{tabular}

Years (y)

*Chi-squared or ANOVA

an individual patient versus obligations to protect the welfare of others and/or comply with institutional policy; and (4) unclear: situations in which there was insufficient information documented in the medical record to determine the type of conflict. For each patient, the clinical context surrounding each ethics reference was described according to both the type(s) of treatment and the type(s) of conflict involved. Categories within each schema were not mutually exclusive; that is, the clinical context related to an ethics reference could include multiple types of treatment and/or multiple types of conflict. Representative quotations from chart notes illustrating each schematic category are presented in Table 2.

Circumstances prompting clinicians to consider an ethics consultation pertained to decisions about code status in 300 patients $(37.8 \%)$, dialysis in 433 patients $(54.5 \%)$, other invasive treatments in 322 patients $(40.6 \%)$, and noninvasive treatments in 485 patients $(61.1 \%)$. These circumstances involved conflicts in stakeholder preferences in 630 patients $(79.3 \%)$, uncertainty about decision-making authority in 444 patients $(55.9 \%)$, and resource/policy issues in 84 patients (10.6\%). In 42 patients $(5.3 \%)$, the type of conflict was unclear. In more than half of cases, circumstances prompting clinicians to consider an ethics consultation involved decisions about more than one treatment (450 patients, 56.7\%) and more than one type of conflict (366 patients, 46.1\%) (Fig. 2). The most frequent combinations involved dialysis and other invasive treatments (174 patients, 21.9\%) and differing treatment preferences and uncertainty about decision-making authority (331 patients, 41.7\%). The frequencies of types of ethical conflict did not vary substantially by the type of treatment being considered (Table 3 ).

\section{End-of-life Care}

Among decedents $(n=20,583)$, patients for whom clinicians had considered an ethics consultation were less likely to have received dialysis compared with patients for whom there was not documentation to suggest clinicians had considered an ethics consultation (48.6\% versus $62.0 \%$, respectively, adjusted odds ratio [aOR] 0.63 , 95\% CI $0.53-0.74$ ) (Table 4). Among those who had received dialysis, patients for whom clinicians had considered an ethics consultation were more likely to have discontinued dialysis treatments before death $(32.5 \%$ versus $20.9 \%$, respectively, aOR 2.07 , 95\% CI 1.61-2.66). Patients for whom clinicians had considered an ethics consultation were also less likely to have received an intensive procedure during the final month of life (8.9\% versus $18.9 \%$, respectively, aOR 0.41 , 95\% CI $0.32-$ $0.54)$. We did not find a significant difference in hospice enrollment between groups $(16.4 \%$ versus $20.0 \%$, respectively, aOR 0.85 , 95\% CI 0.69-1.05).

\section{DISCUSSION}

In this national cohort of patients with advanced kidney disease, $2.8 \%$ of members had documentation in their medical record indicating that clinicians had considered an ethics consultation. Ethical concerns most often pertained to disagreement between patients, their surrogates, and/or clinicians about preferences for dialysis and other life-prolonging treatments. These situations were complex, commonly involving decisions about multiple types of treatment and ethical conflicts. Patients for whom clinicians had considered an ethics consultation were less likely to have been treated with dialysis or to have received intensive patterns of care near the end-of-life.

Clinicians tended to consider an ethics consultation more often among patients with multimorbidity, and ethical 
Table 2 Classification of Circumstances Prompting Clinicians to Seek an Ethics Consultation

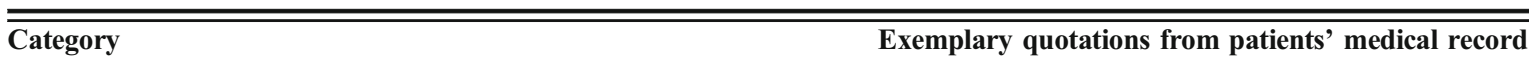

Type of treatment

Dialysis: concerns pertaining to starting, continuing, or stopping

dialysis, or related procedures including dialysis access

Code status: concerns pertaining to Do Not Resuscitate or Full Code status

Other invasive treatments: concerns pertaining to starting, continuing, or stopping mechanical ventilation, surgery, and/or artificial enteral nutrition

Noninvasive treatments: concerns pertaining to other therapies (i.e., peripheral venous access, blood products, antibiotics, hospice, hospital disposition)

Types of conflict

Treatment preferences conflict: uncertainty or disagreement about preferences for treatment(s) between or among patients, their surrogates, family members, and/or clinicians

Decision-making authority conflict: uncertainty or disagreement about the patient's decision-making capacity, who should serve as their surrogate, and/or the role of the surrogate

Policy/resources conflict: conflict between meeting the care needs of an individual patient versus obligations to protect the welfare of others and/ or comply with institutional policy
"Patient needs hemodialysis to address his electrolytes changes, uremia, secondary hyperparathyroidism, which he continues to refuse."

"It is documented that the veteran did not want dialysis, and the veteran's grandson is attempting to override veteran's wishes."

"Why should we continue dialysis in a patient who has a very poor prognosis and certainly a poor quality of life?"

"Patient will remain a full code status patient secondary to lack of family consensus."

"Family still wishes "full code," but that is futile."

"He would not likely have a good result from cardiac resuscitation in case of arrest, [but the patient's] sister felt strongly that he should remain a full code despite our concerns and reservations."

"[The doctor] had extensive discussions with [the power of attorney] ... about the grave prognosis and withdrawal of ventilation support, however she is not able to make the decision. Requesting a third opinion."

"Orthopedics recommends removal of the prosthetic joint ... and the patient expressed his interest in treating the infection. His family, however, does not want him to have surgery to treat the knee infection."

"Concern was that the patient frequently pulled tubes including nasogastric tube and placing a percutaneous gastric tube would be hazardous."

"Similar dilemmas regarding lack of informed consent documentation for blood transfusions have occurred in this nursing unit before, and the problem deserves a global review of the informed consent policy and evaluation of compliance with the policy."

"Spent several hours with [the patient] and team in attempt to determine [the patient's] capacity to accept/refuse peripherally inserted central catheter. $\mathrm{He}$ was very somnolent and hard of hearing making interview difficult." "Unfortunately, no good options if patient is competent and declines assisted living and doesn't have a safe choice at home."

"Recently discharged with the understanding that the patient was to be 'comfortable and that no life sustaining measures be pursued', however, patient's wife is the durable power of attorney now stating she would like the patient [to be] full code and to have dialysis."

"[Patient] does wish to be full code...it is my opinion that employing resuscitative measures for this patient would prove futile."

"Ethics concern raised by [the doctors]: Patient does not understand ramifications of refusing dialysis."

"Given the patient's...underlying psychiatric disorder(s), is it ethically justified to allow him to continue to direct his own healthcare decisions?" "There has been some confusion regarding exactly who the [power of attorney] is... although the brother has re-surfaced with paperwork indicating that he is Medical Power of Attorney, this is not a legal document."

"If at some point, team finds that son is not acting in veteran's best interest, could submit formal consult to ethics committee to re-address advance directives issues."

"A transplantable kidney is an extremely valuable resource. To place a transplantable kidney into a potentially non-compliant patient represents and unfortunate waste of resources."

"Attempts to place catheters will put the patient at increased risk (and potentially increased risk to other patients) and there is no longer any realistic option to continue."

"The medical staff has concern about his having acute bed status, and rightly so...Perhaps persons who manage bed availability within the institution could look at this and make some exception to the normal way of doing business. Perhaps we need to rethink how to best care for those patients who find themselves in our hands and unable to care for themselves by rethinking our practices." concerns commonly involved decisions about more than one type of treatment and related to multiple different medical specialties. Prior work has described how medical decisionmaking is increasingly organized into disease-specific siloes in which specialists (e.g., nephrology, pulmonology, surgery) provide treatment recommendations (e.g., dialysis, mechanical ventilation, amputation) that fall within their narrow scope of practice. ${ }^{32}$ This disease-based approach can lead to fragmented care and conflicting treatment recommendations, especially for patients with multimorbidity. ${ }^{33,34}$ Our findings offer the additional insight that caring for complex patients is also more likely to involve ethical conflict, a finding that reenforces the need for a whole-person and team-based approach to care. $^{30,35}$

Members of our cohort for whom clinicians had considered an ethics consultation were less likely to have received dialysis or other intensive treatments near the end of life, which suggests that ethical uncertainty is more common around decisions to limit life-prolonging treatments. Intensive 


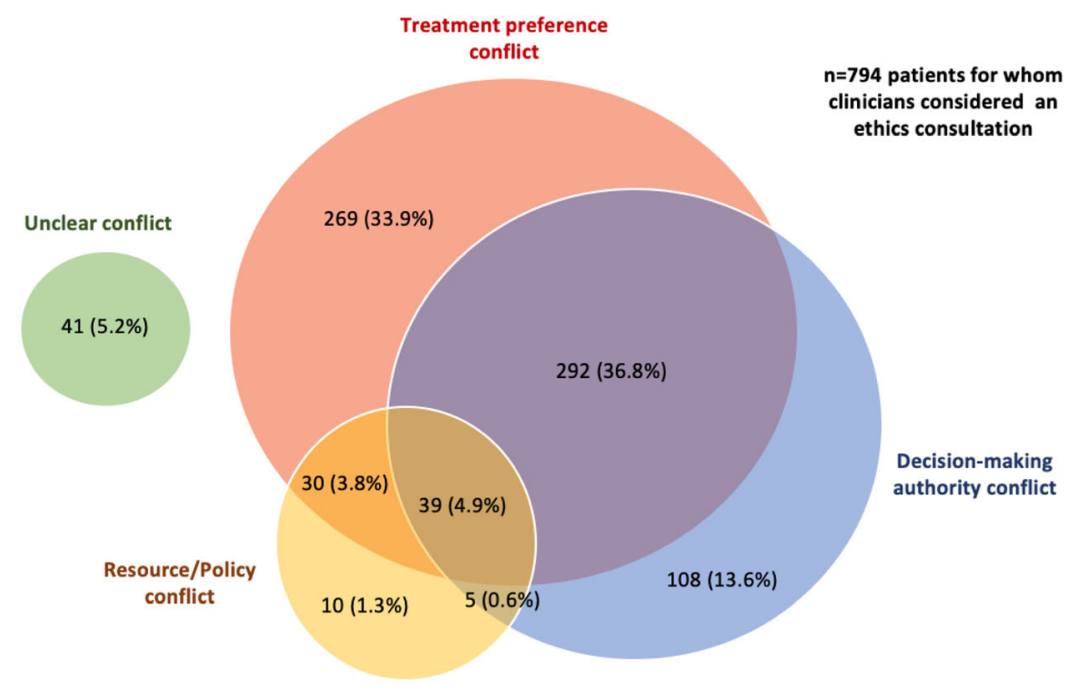

a

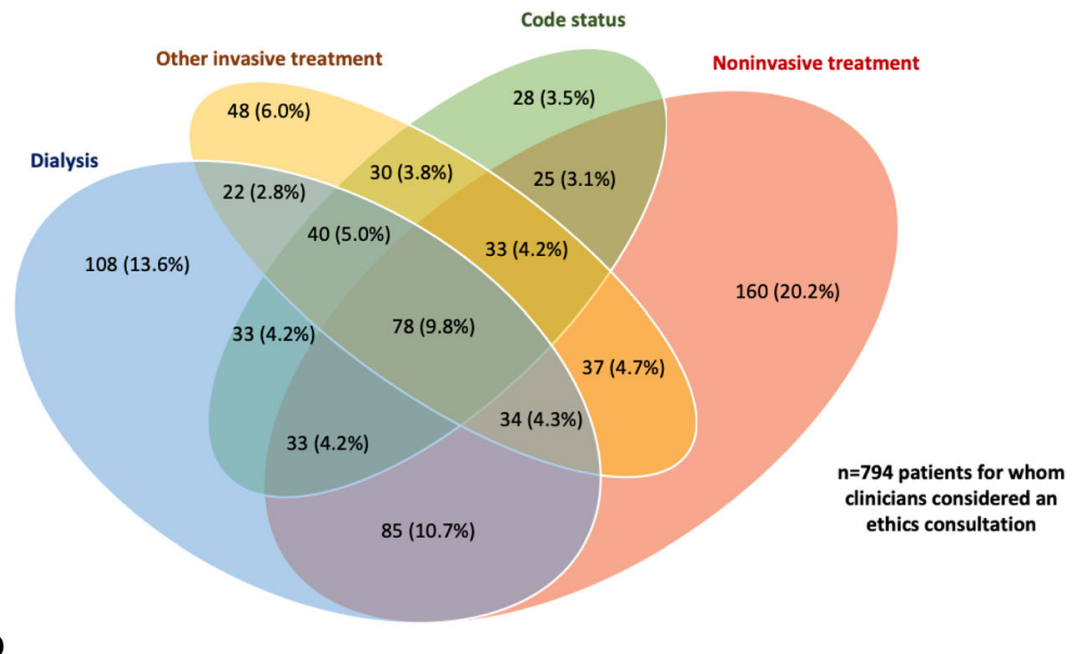

Figure 2 Types of treatments and conflicts involved in circumstances prompting clinicians to consider and/or complete an ethics consultation. These figures illustrate the overlap of (a) types of ethical conflict and (b) types of treatments involved in ethical conflict among patients in whom an ethics consultation was sought.

treatments, such as surgery, dialysis, CPR, mechanical ventilation, and artificial nutrition, have the potential to prolong life and often serve as the default decision in serious illness. We found that clinicians were more likely to have considered an ethics consultation among patients who did not receive life-prolonging treatments. This supports prior work suggesting that there are powerful defaults favoring receipt of these procedures and that decisions to forgo life-prolonging treatments can be contentious and bring about moral uncertainty and distress. ${ }^{36-42}$ We also observed that when there was disagreement about the treatment approach between stakeholders, clinicians also commonly questioned whether patients and family members had authority to make these decisions. This pattern underscores the unease and moral uncertainty that can arise when preferences do not conform with mainstream practice. ${ }^{40}$

Our findings also identify several groups within the population of patients with advanced kidney disease for whom ethical
Table 3 Co-occurrence of Types of Treatments and Types of Conflicts Among Patients for Whom Clinicians Sought an Ethics Consultation

\begin{tabular}{|c|c|c|c|c|}
\hline \multirow[b]{2}{*}{$\begin{array}{l}\text { Type of } \\
\text { conflict }\end{array}$} & \multicolumn{4}{|c|}{ Type of treatment } \\
\hline & $\begin{array}{l}\text { Code status } \\
n=300(\%)\end{array}$ & $\begin{array}{l}\text { Dialysis } \\
n=433(\%)\end{array}$ & $\begin{array}{l}\text { Other } \\
\text { invasive } \\
\text { treatment } \\
n=322(\%)\end{array}$ & $\begin{array}{l}\text { Noninvasive } \\
\text { treatment } \\
n=485(\%)\end{array}$ \\
\hline $\begin{array}{l}\text { Treatment } \\
\text { preferences }\end{array}$ & $254(84.7)$ & $363(83.8)$ & $273(84.8)$ & $374(77.1)$ \\
\hline $\begin{array}{l}\text { Decision- } \\
\text { making } \\
\text { authority }\end{array}$ & $192(64.0)$ & $267(61.7)$ & $186(57.8)$ & $279(57.5)$ \\
\hline $\begin{array}{l}\text { Policy/ } \\
\text { resources }\end{array}$ & $16(5.3)$ & $58(13.4)$ & $24(7.4)$ & $57(11.8)$ \\
\hline Unclear & $9(3.0)$ & $9(2.1)$ & $13(4.0)$ & $31(6.4)$ \\
\hline
\end{tabular}

The entire group of patients in whom clinicians sought an ethics consultation is stratified by type of treatment involved in the ethical conflict (rows). Column percentages reflect percent of cases that involved the specified type of conflict among all cases involving the specified type of treatment. Categories of treatment and type of conflict are not mutually exclusive 
Table 4 Patterns of Care Among Decedents Stratified by Whether or Not Clinicians Sought an Ethics Consultation

\begin{tabular}{|c|c|c|c|}
\hline & $\begin{array}{l}\text { Patients without chart reference } \\
\text { to ethics consultation, }(\%) \\
n=19,889\end{array}$ & $\begin{array}{l}\text { Patients for whom clinicians sought } \\
\text { ethics consultation, }(\%) \\
n=694\end{array}$ & aOR* $(95 \%$ CI $)$ \\
\hline Received dialysis & $12,329(62.0)$ & $330(48.6)$ & $0.63(0.53-0.74)$ \\
\hline Discontinued dialysis $^{\dagger}$ & $2412(20.9)$ & $98(32.5)$ & $2.07(1.61-2.66)$ \\
\hline \multicolumn{4}{|l|}{ Care during the last month of life } \\
\hline Any procedure & $3751(18.9)$ & $62(8.9)$ & $0.41(0.32-0.54)$ \\
\hline Cardiopulmonary resuscitation & $1677(8.4)$ & $21(3.0)$ & $0.32(0.21-0.51)$ \\
\hline Mechanical ventilation & $2937(14.8)$ & $44(6.3)$ & $0.39(0.28-0.53)$ \\
\hline Artificial enteral nutrition & $314(1.6)$ & $14(2.0)$ & $1.35(0.78-2.33)$ \\
\hline Hospice enrollment & $3968(20.0)$ & $114(16.4)$ & $0.85(0.69-1.05)$ \\
\hline
\end{tabular}

Adjusted odds ratio (aOR)

*Adjusted for age at cohort entry (continuous), sex, race, all listed individual comorbidities, year of cohort entry (continuous), comorbidity score (continuous)

†Among decedents who started dialysis as evidenced by USRDS enrollment

conflicts in clinical care may be especially common. Clinicians were more likely to have considered an ethics consultation for patients with cognitive and psychiatric conditions, which may reflect heightened uncertainty about the right course of action when there is concern that illness limits a patient's ability to express his or her personal preferences. ${ }^{8,43-46}$ Additionally, patients for whom clinicians had considered an ethics consultation were less likely to be white. This finding is consistent with prior literature demonstrating systematic challenges in accommodating varied cultural preferences and practices in a healthcare system composed disproportionately of white clinicians. ${ }^{47-49}$ It is also important to recognize that these patterns may reflect value conflicts introduced by implicit bias which can shape how certain patients are treated and whether and under what circumstances life-prolonging interventions are offered. ${ }^{50,51}$

Our study distinguishes itself from prior work by its national scope, large sample size, and innovative methods using the electronic medical record and a novel search tool to comprehensively identify and characterize ethical concerns arising in real-world clinical settings prompting clinicians to consider an ethics consultation. These features increase our confidence that our findings reflect a wide scope of clinical contexts and types of ethical concerns in the care of patients with advanced kidney disease. Nonetheless, these findings should be interpreted with several limitations in mind. First, our analysis only includes ethical conflicts that escalated to the point that clinicians documented having considered an ethics consultation, which likely represents the "tip of the iceberg" of all ethical challenges arising in the care of patients with advanced kidney disease. Our findings also do not capture any episodes of care outside the VA for which an ethics consultation was considered. Second, the VA serves predominantly male, white, and socioeconomically disadvantaged Veterans. Hence, our findings may not be generalizable to groups not wellrepresented in the VA and may not reflect practices occurring in other health systems. Third, owing to the complexity of ethical concerns, multiple concurrent treatment decisions, and shifting treatment preferences over time, it was not possible to dichotomize each stakeholder's position in favor of or against particular treatments. Finally, this analysis was based on medical record notes, which were limited to content that clinicians chose to document and may not fully or accurately reflect the perspectives of patients, their surrogates, and clinicians.

\section{CONCLUSION}

Among patients with advanced kidney disease, ethical concerns prompting clinicians to consider an ethics consultation arose most commonly when there was conflict between patients, their surrogates, and clinicians about preferences for dialysis and other life-prolonging treatments. Patients for whom clinicians considered an ethics consultation received less-intensive patterns of care than those without such documentation. Collectively, these findings reflect serious ethical uncertainty about life-prolonging treatments in patients with advanced kidney disease-especially when these treatments are not pursued. This underscores the importance of a person-centered and team-based approach to medical decision-making that can accommodate pluralism in values and preferences

Corresponding Author: Catherine R. Butler, MD; Division of Nephrology, Department of Medicine University of Washington, Seattle, WA, USA (e-mail: cathb@nephrology.washington.edu).

Funding Information This work is supported by grants from the National Institute of Health (5T32DK007467-33, Butler; 1K23DK107799-01A1, Wong) and VA Health Services Research and Development (IIR 09-094, PI Hebert; and IIR 12-126, O'Hare). Dr. Wong also receives funding from the National Palliative Care Research Center and VA National Center for Ethics in Health Care. The sponsors had no role in the design and conduct of the study; in collection, management, analysis, or interpretation of the data; in preparation, review, or approval of the manuscript; or decision to submit for publication.

\section{Compliance with Ethical Standards:}

The Institutional Review Boards at the VA Puget Sound Health Care System and the University of Washington approved this study and waived the requirement for informed consent. 
Conflict of Interest: The authors declare that they do not have a conflict of interest.

\section{REFERENCES}

1. Butler CR, Mehrotra R, Tonelli MR, Lam DY. The Evolving Ethics of Dialysis in the United States: A Principlist Bioethics Approach. Clin J Am Soc Nephrol 2016;11(4):704-709.

2. Gostin LO. Deciding life and death in the courtroom. From Quinlan to Cruzan, Glucksberg, and Vacco-a brief history and analysis of constitutional protection of the 'right to die'. JAMA. 1997;278(18):1523-1528.

3. Ramer SJ, McCall NN, Robinson-Cohen C, et al. Health Outcome Priorities of Older Adults with Advanced CKD and Concordance with Their Nephrology Providers' Perceptions. J Am Soc Nephrol 2018; Dec 29(12):2870-2878.

4. Wachterman MW, Marcantonio ER, Davis RB, et al. Relationship between the prognostic expectations of seriously ill patients undergoing hemodialysis and their nephrologists. JAMA Intern Med 2013;173(13):1206-1214.

5. Wright AA, Keating NL, Ayanian JZ, et al. Family Perspectives on Aggressive Cancer Care Near the End of Life. JAMA. 2016;315(3):284-292.

6. Wright AA, Zhang B, Ray A, et al. Associations between end-of-life discussions, patient mental health, medical care near death, and caregiver bereavement adjustment. JAMA. 2008;300(14):1665-1673.

7. Lamiani G, Borghi L, Argentero $\mathbf{P}$. When healthcare professionals cannot do the right thing: A systematic review of moral distress and its correlates. J Health Psychol 2017;22(1):51-67.

8. Shared decision-making in the appropriate initiation of and withdrawal from dialysis. Rockville, MD: Renal Physicians Association; 2010.

9. Kurella Tamura M, Desai M, Kapphahn KI, Thomas IC, Asch SM, Chertow GM. Dialysis versus Medical Management at Different Ages and Levels of Kidney Function in Veterans with Advanced CKD. J Am Soc Nephrol 2018;29(8):2169-2177.

10. O'Connor NR, Kumar P. Conservative management of end-stage renal disease without dialysis: a systematic review. J Palliat Med 2012;15(2):228-235.

11. Kurella Tamura M, Thomas IC, Montez-Rath ME, et al. Dialysis Initiation and Mortality Among Older Veterans With Kidney Failure Treated in Medicare vs the Department of Veterans Affairs. JAMA Intern Med 2018;178(5):657-664.

12. Tonelli M, Wiebe N, Manns BJ, et al. Comparison of the Complexity of Patients Seen by Different Medical Subspecialists in a Universal Health Care System. JAMA Netw Open. 2018 Nov 2;1(7):e184852

13. Wong SP, Kreuter W, O'Hare AM. Healthcare intensity at initiation of chronic dialysis among older adults. J Am Soc Nephrol 2014;25(1):143-149.

14. Wong SP, Kreuter W, Curtis JR, Hall YN, O'Hare AM. Trends in inhospital cardiopulmonary resuscitation and survival in adults receiving maintenance dialysis. JAMA Intern Med 2015;175(6):1028-1035.

15. Holley JL, Kirk J. Enteral tube feeding in a cohort of chronic hemodialysis patients. J Ren Nutr 2002;12(3):177-182.

16. Courtwright A, Jurchak M. The Evolution of American Hospital Ethics Committees: A Systematic Review. J Clin Ethics 2016;27(4):322-340.

17. VHA Directive 1004.06: IntegratedEthics. National Center for Ethics in Health Care. 2018.

18. National Center for Ethics in Health Care, Ethics Consultation: Responding to Ethics Questions in Health Care. 2nd ed. Washington, DC: U.S. Department of Veterans Affairs; 2015.

19. National Center for Ethics in Health Care: National Ethics Consultation Service. Available at: https://www.ethics.va.gov/activities/consult.asp. Accessed 9 July 2019.

20. DuVal G, Sartorius L, Clarridge B, Gensler G, Danis M. What triggers requests for ethics consultations? J Med Ethics 2001;27 Suppl 1:i24-29.

21. DuVal G, Clarridge B, Gensler G, Danis M. A national survey of U.S. internists' experiences with ethical dilemmas and ethics consultation. J Gen Intern Med 2004; 19(3):251-258.

22. Wasson K, Anderson E, Hagstrom E, McCarthy M, Parsi K, Kuczewski M. What Ethical Issues Really Arise in Practice at an Academic Medical Center? A Quantitative and Qualitative Analysis of Clinical Ethics Consultations from 2008 to 2013. HEC Forum 2016;28(3):217-228.

23. Johnson LS, Lesandrini J, Rozycki GS. Use of the medical Ethics Consultation Service in a busy Level I trauma center: impact on decisionmaking and patient care. Am Surg 2012;78(7):735-740.
24. Voigt LP, Rajendram P, Shuman AG, et al. Characteristics and Outcomes of Ethics Consultations in an Oncologic Intensive Care Unit. J Intensive Care Med 2015;30(7):436-442.

25. Bruce CR, Smith ML, Hizlan S, Sharp RR. A systematic review of activities at a high-volume ethics consultation service. J Clin Ethics 2011;22(2):151-164.

26. Wong SP, Hebert PL, Laundry RJ, et al. Decisions about Renal Replacement Therapy in Patients with Advanced Kidney Disease in the US Department of Veterans Affairs, 2000-2011. Clin J Am Soc Nephrol 2016;11(10):1825-1833.

27. Wong SPY, Yu MK, Green PK, Liu C-F, Hebert PL, O'Hare AM. End-of-Life Care for Patients With Advanced Kidney Disease in the US Veterans Affairs Health Care System, 2000-2011. Am J Kidney Dis 2018;72(1):42-49.

28. Gagne JJ, Glynn RJ, Avorn J, Levin R, Schneeweiss S. A combined comorbidity score predicted mortality in elderly patients better than existing scores. J Clin Epidemiol 2011;64(7):749-759.

29. Hammond KW, Laundry R, O'Leary TM, Jones WP. Use of text search to effectively identify lifetime prevalence of suicide attempts among veterans. Presented at the SystemSciences (HICSS) 2013 46th Hawaii International Conference on SystemSciences. In: 2013.

30. Boyd C, Smith CD, Masoudi FA, et al. Framework for Decision-making for Older Adults with Multiple Chronic Conditions: Executive Summary of Action Steps for the AGS Guiding Principles on the Care of Older Adults with Multimorbidity. J Am Geriatr Soc 2019.

31. Krippendorff K. Content Analysis: An Introduction to Its Methodology. 3rd ed. Thousand Oaks: Sage Publications; 2013.

32. Tinetti ME, Fried T. The end of the disease era. Am $\mathrm{J}$ Med 2004;116(3): 179-185.

33. Wang V, Diamantidis $\mathbf{C}$, Wylie $\mathbf{J}$, Greer RC. Minding the gap and overlap: a literature review of fragmentation of primary care for chronic dialysis patients. BMC Nephrol 2017;18(1):274.

34. Boyd CM, Darer J, Boult C, Fried LP, Boult L, Wu AW. Clinical practice guidelines and quality of care for older patients with multiple comorbid diseases: implications for pay for performance. JAMA. 2005;294(6):716724.

35. Davison SN, Torgunrud C. The creation of an advance care planning process for patients with ESRD. Am J Kidney Dis 2007;49(1):27-36.

36. Grubbs V, Tuot DS, Powe NR, O'Donoghue D, Chesla CA. System-Level Barriers and Facilitators for Foregoing or Withdrawing Dialysis: A Qualitative Study of Nephrologists in the United States and England. Am J Kidney Dis 2017;70(5):602-610.

37. Ladin K, Pandya $\mathbf{R}$, Kannam A, et al. Discussing Conservative Management With Older Patients With CKD: An Interview Study of Nephrologists. Am J Kidney Dis 2018;71(5):627-635.

38. Russ AJ, Shim JK, Kaufman SR. The value of "life at any cost": talk about stopping kidney dialysis. Soc Sci Med 2007;64(11):2236-2247.

39. Halpern SD, Loewenstein G, Volpp KG, et al. Default options in advance directives influence how patients set goals for end-of-life care. Health Aff (Millwood) 2013;32(2):408-417.

40. Kaufman S. Ordinary Medicine: Extraordinary Treatments, Longer Lives, and Where to Draw the Line. Durham: Duke University Press; 2015.

41. Approaching Death: Improving Care at the End of Life. Washington DC, National Academy of Sciences; 1997.

42. Wong SPY, McFarland LV, Liu CF, Laundry RJ, Hebert PL, O'Hare AM. Care Practices for Patients With Advanced Kidney Disease Who Forgo Maintenance Dialysis. JAMA Intern Med. 2019;179(3):305-313.

43. Baumrucker SJ, York P, Stolick M, et al. Autonomy and Withdrawal of Treatment in a Patient With Depression. Am J Hosp Palliat Care 2018;35(6):908-914.

44. Fetherstonhaugh D, McAuliffe L, Bauer M, Shanley C. Decisionmaking on behalf of people living with dementia: how do surrogate decision-makers decide? J Med Ethics 2017;43(1):35-40.

45. Dementia: ethical issues. Cambridge: Nuffield Council on Bioethics; 2009.

46. Singer PA. Nephrologists' experience with and attitudes towards decisions to forego dialysis. The End-Stage Renal Disease Network of New England. J Am Soc Nephrol 1992;2(7):1235-1240.

47. Kwak J, Haley WE. Current research findings on end-of-life decision making among racially or ethnically diverse groups. Gerontologist. 2005;45(5):634-641.

48. Hopp FP, Duffy SA. Racial variations in end-of-life care. J Am Geriatr Soc 2000;48(6):658-663.

49. Loggers ET, Maciejewski PK, Paulk E, et al. Racial differences in predictors of intensive end-of-life care in patients with advanced cancer. $J$ Clin Oncol 2009;27(33):5559-5564. 
50. Chapman EN, Kaatz A, Carnes M. Physicians and implicit bias: how doctors may unwittingly perpetuate health care disparities. J Gen Intern Med 2013;28(11):1504-1510.

51. FitzGerald C, Hurst S. Implicit bias in healthcare professionals: a systematic review. BMC Med Ethics 2017;18(1):19.

Publisher's Note Springer Nature remains neutral with regard to jurisdictional claims in published maps and institutional affiliations. 